\title{
Electroluminescence Properties of a Zinc Oxide Nanorod Array Heterojunction Light-Emitting Diode
}

\author{
HUA JIANG,${ }^{1}$ YOUMING LU, ${ }^{1,2}$ XIMING RONG $\mathbb{C},{ }^{1,3}$ SHUN HAN, ${ }^{1}$ \\ PEIJIANG CAO,${ }^{1}$ YUXIANG ZENG, ${ }^{1}$ WANGYING XU,${ }^{1}$ MING FANG,${ }^{1}$ \\ WENJUN LIU, ${ }^{1}$ and DELIANG ZHU ${ }^{1}$ \\ 1.-College of Materials Science and Engineering, Shenzhen Key Laboratory of Special Functional \\ Materials, Shenzhen Engineering Laboratory for Advanced Technology of Ceramics, Guangdong \\ Research Center for Interfacial Engineering of Functional Materials, Shenzhen University, \\ Shenzhen 518060, China. 2.—e-mail: ymlu@szu.edu.cn. 3.—e-mail: xmrong@szu.edu.cn
}

\begin{abstract}
A $p-\mathrm{GaN} / i-\mathrm{MgO} / n-\mathrm{ZnO}$ nanorod array (NRA) heterojunction light-emitting diode has been fabricated. Its room-temperature electroluminescence spectra under different forward biases revealed a strong emission band across the whole visible region, which was blue-shifted when increasing the forward bias. The origin of this visible emission is considered to be related to oxygen vacancy $\left(V_{\mathrm{O}}\right)$ defects in different valence states, where the blue emission $(\sim 460 \mathrm{~nm})$ comes from neutral oxygen vacancy $\left(V_{\mathrm{O}}^{\mathrm{X}}\right)$ defects and the green emission $(\sim 520 \mathrm{~nm})$ from singly charged oxygen vacancy $\left(V_{\mathrm{O}}^{+}\right)$defects, while the yellow $(\sim 580 \mathrm{~nm})$ and red emission $(\sim 670 \mathrm{~nm})$ are attributed to doubly charge oxygen vacancy $\left(V_{\mathrm{O}}^{++}\right)$defects. These $V_{\mathrm{O}}$ defects in different states can convert into one another under different excitation conditions, resulting in the blueshift of the emission peak as the forward voltage is increased.
\end{abstract}

Key words: $\mathrm{ZnO}$ nanorod array, heterojunction, electroluminescence, oxygen vacancy defect, pulsed laser deposition

\section{INTRODUCTION}

As an important group II-VI compound, zinc oxide $(\mathrm{ZnO})$ has been widely explored for its potential use in solid-state light sources due to its wide bandgap $(3.37 \mathrm{eV})$ and exciton binding energy $(60 \mathrm{meV})$ above room temperature. ${ }^{1-3}$ The ability to grow $\mathrm{ZnO}$ with preferred orientation is another unique advantage, and $\mathrm{ZnO}$ nanorod array (NRA) structures can even be obtained easily using the solution method. ${ }^{4,5}$ Such one-dimensional waveguide-type rod-shaped $\mathrm{ZnO}$ exhibits excellent photoconductivity, and $\mathrm{ZnO}$-based light-emitting diodes (LEDs) based on such structures have been studied extensively in recent years. ${ }^{6-13}$ Although the luminescent properties of $\mathrm{ZnO}$-based LED devices with

(Received November 13, 2019; accepted January 9, 2020; published online January 23, 2020) different structures are not the same due to differences in their structure and fabrication processes, they can be roughly classified into those exhibiting ultraviolet emission originating from excitons ${ }^{12}$ and those showing visible luminescence associated with impurities or defects. ${ }^{14}$

For luminescence caused by defects, the greatest controversy regards the origin of the luminescence in the visible region. Due to the rich intrinsic defects in $\mathrm{ZnO}$ materials, luminescence related to various types of defect has been reported, including oxygen vacancies $\left(V_{\mathrm{O}}\right)$, interstitial oxygen $\left(\mathrm{O}_{\mathrm{i}}\right)$, zinc vacancies $\left(V_{\mathrm{Zn}}\right)$, interstitial zinc $\left(\mathrm{Zn}_{\mathrm{i}}\right)$, etc. ${ }^{15-24}$ As early as 1996, Vanheusde et al. demonstrated that the green ( $510 \mathrm{~nm}$ ) emission from $\mathrm{ZnO}$ is caused by singly charged oxygen vacancies $\left(V_{\mathrm{O}}^{+}\right)$, and they found that free-carrier depletion can strongly influence its emission intensity, particularly for small parti$\operatorname{cles}^{15}$; Panigrahy et al. established a direct link between the magnetization and the relative occupancy of $V_{\mathrm{O}}^{+}$defects present on the surface of $\mathrm{ZnO}$ 
NRs, ${ }^{16}$ and also confirmed the attribution of the yellow light $(\sim 580 \mathrm{~nm})$ emission to the combination between doubly charge oxygen vacancies $\left(V_{\mathrm{O}}^{++}\right)$for the deep acceptor level and conduction-band electrons, while the blue $(\sim 450 \mathrm{~nm})$ emission may be related to neutral oxygen vacancies $\left(V_{\mathrm{O}}^{\mathrm{X}}\right)$. The origin of the red light emission is controversial, but it is generally considered to be related to interstitial zinc $\left(\mathrm{Zn}_{\mathrm{i}}\right){ }^{6,7,17,19}$ Nanostructured $\mathrm{ZnO}$ materials, apart from a large number of intrinsic defects, also exhibit strong adsorption on their highly active surface, which complicates the visible luminescence. ${ }^{21,25,26}$ In addition, Zhu et al. synthesized $\mathrm{ZnO}$ nanoparticles (NPs) and NRA film by the sol-gel method, confirming that the $\mathrm{ZnO}$ NRA film contained more $V_{\mathrm{O}}$ defects and chemisorbed oxygen, which led to a special charge storage property. ${ }^{26}$ Similarly, $V_{\mathrm{O}}$ defects and chemisorbed oxygen also play an important role in the work described herein.

In this study, a highly vertically oriented onedimensional NRA was prepared on a $p$-type gallium nitride ( $p-\mathrm{GaN})$ substrate by a solution method, and a strong electroluminescence (EL) spectra was observed in the prepared $\mathrm{ZnO}$ NRA heterojunction at room temperature. The resulting band was in the visible region, and as the forward bias was increased, a significant blue-shift was observed in its peak position. By analyzing the correspondence between the different visible light emission bands and $V_{O}$ defects, the visible light emission band can be attributed to $V_{O}$ defects, and its shift to different states of $V_{\mathrm{O}}$.

\section{EXPERIMENTAL PROCEDURES}

An insulating magnesium oxide (i-MgO) layer (temperature $600^{\circ} \mathrm{C}$, oxygen pressure $2 \mathrm{~Pa}$, laser frequency $5 \mathrm{\Theta z}$ ) and $\mathrm{ZnO}$ seed layer (temperature $600^{\circ} \mathrm{C}$, oxygen pressure $3 \mathrm{~Pa}$, laser frequency $3 \mathrm{\Theta z}$ ) were fabricated on a $p$-GaN substrate by the pulsed laser deposition (PLD) method. The $p$-GaN doped with magnesium was synthesized by metalorganic chemical vapor deposition (MOCVD), having carrier concentration and mobility of $3.14 \times 10^{17} \mathrm{~cm}^{-3}$ and $7.96 \mathrm{~cm}^{2} \mathrm{~V}^{-1} \mathrm{~s}^{-1}$, respectively. The vacuum deposition system was a PLD-450 device (SKY Technology Development Company), and the laser was a COMPexPro205 samarium fluoride $(\mathrm{KrF})$ laser $(248 \mathrm{~nm})$ (Lambda Physics Company). The ZnO NRA was prepared by a solution method. Zinc acetate dehydrate $\left(0.01 \mathrm{~mol} \mathrm{~L}^{-1}\right)$ and hexamethyleneimine (HMT, $0.01 \mathrm{~mol} \mathrm{~L}^{-1}$ ) were dissolved in $40 \mathrm{ml}$ deionized water, being left for $24 \mathrm{~h}$ after stirring for $2 \mathrm{~h}$, then the solution was heated to $95^{\circ} \mathrm{C}$. Finally, the substrate with the insulating and seed layers was immersed in the growth solution at a tilt angle of $90^{\circ}$ and grown for $2 \mathrm{~h}$. A gold (Au)/ nickel (Ni) electrode with thickness of $5 \mathrm{~nm} / 5 \mathrm{~nm}$ was prepared by vacuum thermal evaporation then annealed at $500^{\circ} \mathrm{C}$ for 5 min in oxygen atmosphere. The indium (In) electrode was prepared by vacuum sintering. The morphology of the $\mathrm{ZnO}$ NRs was studied by thermal field-emission scanning electron microscopy (SEM, SU-70). The $I-V$ curve of the device and electrode were measured using a UV2450 power supply equipment. EL measurements were carried out using a Zolix ultraviolet-visible (UV-Vis) spectrometer (ZLX-FS Omni $\lambda$-3005), photoluminescence (PL) measuring using a $30-\mathrm{mW}$ helium (He)-cadmium (Cd) laser $(325 \mathrm{~nm})$, and confocal Raman spectrometry (Renishaw inVia model) by placing the samples in a closed-loop liquid-helium refrigerator for temperature-dependent measurements.

\section{RESULTS AND DISCUSSION}

Figure 1a shows a top-view SEM image of the ZnO NRA, while the inset displays an enlarged image from the same perspective. Figure $1 \mathrm{~b}$ shows a SEM image of the $\mathrm{ZnO}$ NRA tilted at a viewing angle of $25^{\circ}$, while the inset shows its cross section, revealing a typical $\mathrm{ZnO} \mathrm{NR}$ with hexagonal structure with length of about $500 \mathrm{~nm}$ and diameter of $50 \mathrm{~nm}$ to $100 \mathrm{~nm}$. Meanwhile, note that, due to the small distance between the ZnO NRs, some of them joined into larger-diameter NRs and even irregularly shaped columns. Figure 1c shows the a schematic of the structure of the $\mathrm{ZnO}$ NRA heterojunction LED, where the thickness of the $\mathrm{MgO}$ is about $15 \mathrm{~nm}$, its main function being to inhibit electron transfer to the $p$-GaN side to achieve more efficient composite emission from the $\mathrm{ZnO}$ side; The thickness of the seed layer $(\mathrm{ZnO})$ was about $85 \mathrm{~nm}$, mainly being used to improve the growth perpendicularity of the $\mathrm{ZnO}$ NRA. Figure 1d shows the $I-V$ curve of the LED device. At reserve bias of $15 \mathrm{~V}$, the current was approximately $2 \mathrm{~mA}$, while under forward bias of $15 \mathrm{~V}$, it exceeded $4 \mathrm{~mA}$. These results show that the device exhibited significant rectification characteristics. The inset shows the $I-V$ curve of the $\mathrm{Au} / \mathrm{Ni}$ electrode, confirming a good ohmic contact.

The room-temperature EL spectra of the prepared $p$-GaN/i-MgO/n-ZnO NRA heterojunction LED are shown in Fig. $2 \mathrm{~g}$, revealing mainly a wide band in the visible region. As the forward bias was increased, the intensity of the band increased and the peak position gradually shifted to shorter wavelength. When the applied bias voltage was $15 \mathrm{~V}$, the center wavelength of the luminescence peak was about $620 \mathrm{~nm}$, but when the bias voltage was increased to $35 \mathrm{~V}$, the center wavelength moved to $525 \mathrm{~nm}$. Figure $2 \mathrm{a}-\mathrm{f}$ shows photographs of the luminescent device at different bias voltages (in a dark environment), where the camera was fixed at $(12 \mathrm{~cm}, 20 \mathrm{~cm}, 15 \mathrm{~cm})$ away from the sample in three-dimensional space $(\sim 28 \mathrm{~cm}$, see inset of Fig. 2a for coordinates). The photographs in Fig. 2a-f display weak red light at bias of $10 \mathrm{~V}$ and yellow emission at bias of $20 \mathrm{~V}$, while the device begins to emit bright white light at bias of $30 \mathrm{~V}$. 

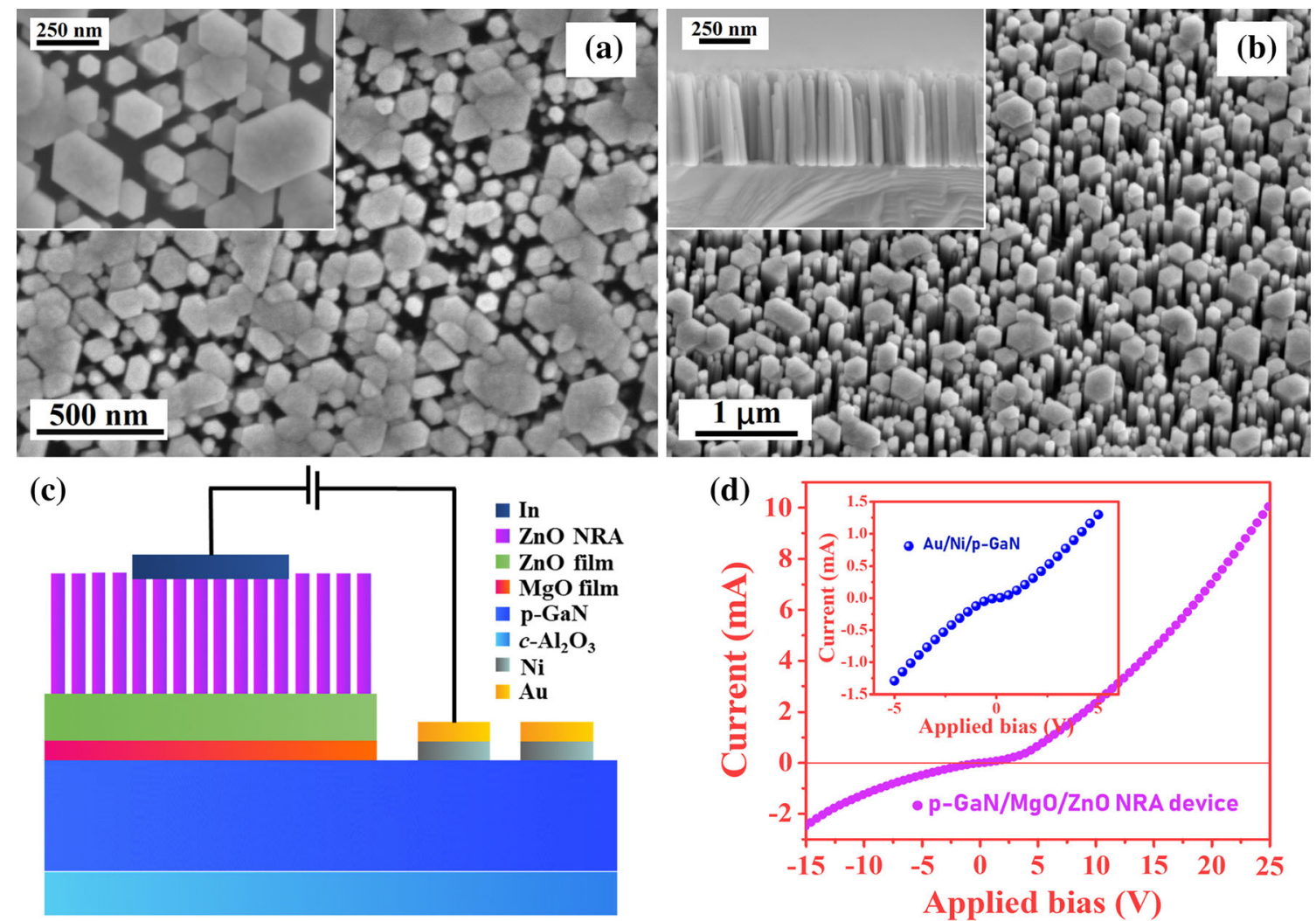

Fig. 1. (a) SEM image of ZnO NRA (inset displays enlarged image from same perspective). (b) SEM image of ZnO NRA tilted at viewing angle of $25^{\circ}$ (inset shows cross section of NRA). (c) Schematic of structure of $p$-GaN/i-MgO/n-ZnO heterojunction LED device. (d) $I-V$ curve of device under different bias voltages (inset confirms good ohmic contact between Au/Ni and $p$-GaN).

To study the causes of the blue-shift of the EL spectrum of the device, we performed temperaturedependent PL spectroscopy on the prepared $\mathrm{ZnO}$ NRA. Firstly, the PL spectrum of the GaN substrate measured at $298 \mathrm{~K}$ is shown in Fig. 3a, revealing an emission band that originates from the doped $\mathrm{Mg}$ acceptor energy level at $440 \mathrm{~nm}$ in $p$-GaN. Comparing the PL spectra of the sample in Fig. 3a, there is only one very broad visible emission band with a central wavelength of $500 \mathrm{~nm}$ to $600 \mathrm{~nm}$. It can be seen that the PL luminescence curve is completely different from that of $p-\mathrm{GaN}$, indicating that the luminescence originates from the $\mathrm{ZnO}$ NRA. The PL luminescence intensity decreased and the peak position changed with increasing temperature. The corresponding peak positions at $298 \mathrm{~K}$ and $773 \mathrm{~K}$ were $\sim 574 \mathrm{~nm}$ and $\sim 544 \mathrm{~nm}$, respectively. Figure $3 \mathrm{~b}$ displays the PL spectra under nitrogencooled condition, while the inset shows the trend of the peak position as a function of temperature, revealing a delayed blue-shift from $78 \mathrm{~K}$ to $773 \mathrm{~K}$. At a certain temperature between $423 \mathrm{~K}$ and $523 \mathrm{~K}$, the peak position changed from $\sim 571 \mathrm{~nm}$ to $\sim 546 \mathrm{~nm}$; we call this the transition temperature for the large change of peak position. In general, Fig. $3 a$ and $b$ demonstrates that the PL spectra presented $\mathrm{a} \sim 30$-nm blue-shift of the peak position overall, of which $\sim 25 \mathrm{~nm}$ occurred at the transition temperature. To clarify why the temperature- dependent PL spectra exhibited such a blue-shift, multipeak fitting was applied. Figure $3 c$ shows the Gaussian fitting results for the PL spectra at $298 \mathrm{~K}$, $523 \mathrm{~K}, 623 \mathrm{~K}$, and $773 \mathrm{~K}$, yielding four visible light emission bands, viz. P1 (blue light $\sim 452 \mathrm{~nm}$ ), P2 (green light $\sim 525 \mathrm{~nm}$ ), P3 (yellow $\sim 590 \mathrm{~nm}$ ), and P4 (red light $\sim 685 \mathrm{~nm}$ ). Comparison of these four visible light emission bands reveals that P2 and P3 were strong, and the relative intensity of $\mathrm{P} 2$ increased with temperature, while gradually P3 decreased. P1 and P4 were weak, with an increasing trend of the relative intensity of $\mathrm{P} 1$ but no obvious change in $\mathrm{P} 4$

Generally, the visible luminescence of $\mathrm{ZnO}$ is attributed to defect-related recombination, while $\mathrm{ZnO}$ NRs grown by the solution method are considered to exhibit a large number of donor-like $V_{\mathrm{O}}$ effects. ${ }^{13,17,27}$ Figure 4 shows the energy level distribution of the $\mathrm{ZnO} \mathrm{NRs}$ according to the fitting results shown in Fig. 3c. In these $\mathrm{ZnO} \mathrm{NRs}$, the energy levels of $V_{\mathrm{O}}^{\mathrm{X}}$ and $V_{\mathrm{O}}^{+}$are $2.74 \mathrm{eV}$ and $2.36 \mathrm{eV}$ higher than the valence-band maximum, respectively, while those of $\mathrm{Zn}_{\mathrm{i}}$ and $V_{\mathrm{O}}^{++}$are $0.29 \mathrm{eV}$ and $2.36 \mathrm{eV}$ lower than the conduction-band minimum. These results are consistent with previous reports. ${ }^{21,26}$

The highly active surface of $\mathrm{ZnO}$ NRs can easily adsorb $\mathrm{O}_{2}$ molecules, which capture electrons from $V_{\mathrm{O}}$, resulting in $V_{\mathrm{O}}^{++}, V_{\mathrm{O}}^{+}$, and $V_{\mathrm{O}}^{\mathrm{X}}$ in different charge 

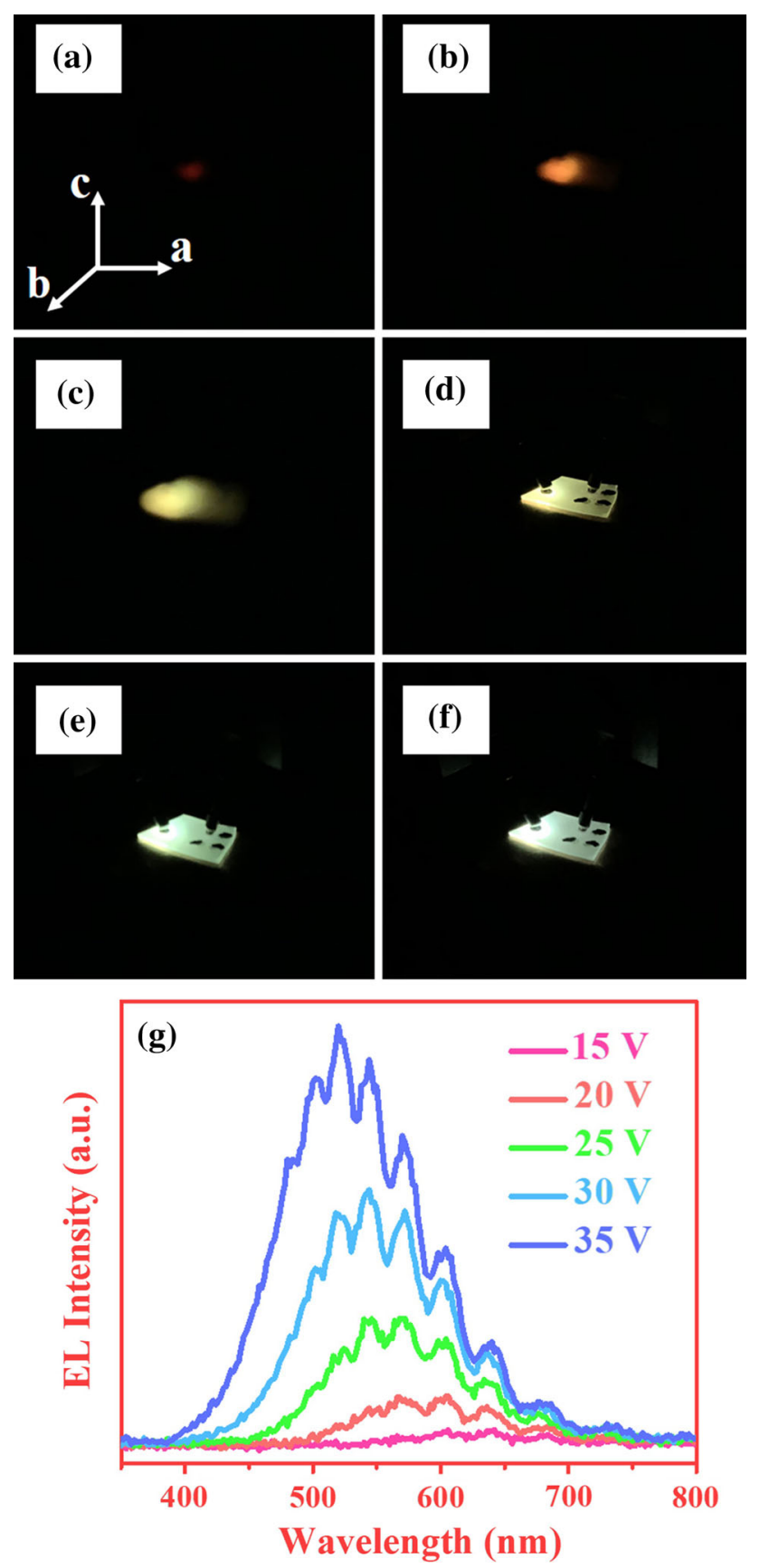

Fig. 2. Photographs of device under forward bias of (a) $10 \mathrm{~V}$, (b) $15 \mathrm{~V}$, (c) $20 \mathrm{~V}$, (d) $25 \mathrm{~V}$, (e) $30 \mathrm{~V}$, and (f) $35 \mathrm{~V}$. (g) EL spectra of the device under forward bias of $15 \mathrm{~V}, 20 \mathrm{~V}, 25 \mathrm{~V}, 30 \mathrm{~V}$, and $35 \mathrm{v}$.

states, as shown in Fig. 5. Under certain external conditions, $V_{\mathrm{O}}$ also exhibits a certain transformation relationship between its different states. ${ }^{4,16,21,26} V_{\mathrm{O}}^{+}$can be converted into $V_{\mathrm{O}}^{++}$by capturing a hole, or into $V_{\mathrm{O}}^{\mathrm{X}}$ by capturing an electron. Under strong irradiation, $V_{\mathrm{O}}^{++}$can also be converted into $V_{\mathrm{O}}^{+}{ }^{15}$ Figure 6 shows the $V_{\mathrm{O}}$ distribution of the $\mathrm{ZnO} \mathrm{NRs}$ from the surface to bulk. Closer to the surface, the electrons of $V_{\mathrm{O}}$ are trapped more easily by adsorbed $\mathrm{O}_{2}$, resulting in a lower electron concentration near the surface, which forms a surface depletion region of a certain thickness. ${ }^{21,26}$ The thickness of this depletion layer can change the distribution of $V_{\mathrm{O}}$ in different states. Also, its thickness can be calculated as

$$
W=\left(\frac{2 \varepsilon_{\mathrm{ZnO}} V_{\mathrm{bi}}}{e N_{\mathrm{D}}}\right)^{1 / 2}
$$

where $\varepsilon_{\mathrm{ZnO}}$ is the static dielectric constant of $\mathrm{ZnO}$, $V_{\mathrm{bi}}$ is the boundary electric potential, $e$ is the electron charge, and $N_{\mathrm{D}}$ represents the charge density of the depletion layer. ${ }^{15}$ This formula reveals that the boundary electric potential and the carrier concentration directly affect the thickness of the depletion layer. At room temperature, surface adsorption will increase the boundary electric potential of the $\mathrm{ZnO} \mathrm{NRs}$, while the photogenerated carrier concentration is lower, so the thickness of the depletion layer of the $\mathrm{ZnO} \mathrm{NRs}$ is larger, and the $V_{\mathrm{O}}$ defects are dominated by $V_{\mathrm{O}}^{++}$, resulting in strong P3 emission. As the temperature increases, the carrier concentration rises rapidly since the intrinsic excitation of $\mathrm{ZnO}$ increases, which narrows the depletion layer. ${ }^{15,21,26}$ Then, the $V_{O}^{++}$decrease while the $V_{\mathrm{O}}^{+}$increase, and the P2 emission gradually increases, eventually exceeding P3 at $773 \mathrm{~K}$. Limited by the thermal resistance of the device, we were unable to measure PL spectra at higher temperatures, and no further enhancement of the P1 emission band could be observed.

For comparison with the PL spectra, the Gaussian fitting of the EL spectra is presented in Fig. 7: the E3 (yellow, $\sim 580 \mathrm{~nm}$ ) and E4 (red, $\sim 670 \mathrm{~nm}$ ) emission bands appeared at $15 \mathrm{~V}$; the E2 (green, $\sim 520 \mathrm{~nm}$ ) emission band appeared at $25 \mathrm{~V}$; the E2 emission band gradually increased with increasing voltage, exceeding E3 at $35 \mathrm{~V}$; eventually, at bias voltage to $90 \mathrm{~V}$, a strong E1 (blue, $\sim 462 \mathrm{~nm}$ ) emission band resulted. Similar to the PL mechanism, in the EL measurements, when the bias voltage was small, the injected carrier concentration was low and the depletion layer of the $\mathrm{ZnO}$ NRs was wide or it was even completely depleted. ${ }^{26}$ In this condition, the $V_{\mathrm{O}}$ defects are mainly in the $V_{\mathrm{O}}^{++}$state, and the whole device emits yellow light $(\sim 580 \mathrm{~nm})$ visible to the naked eye; as the bias voltage is increased, the injected carrier concentration gradually increases and the depletion layer shrinks. So the $V_{\mathrm{O}}^{++}$decrease, the $V_{\mathrm{O}}^{+}$increase, and the green emission $(\sim 580 \mathrm{~nm})$ band appears, so the device emits bright white light; when the bias voltage is larger, the depletion layer is further narrowed, and due to the higher concentration of injected carriers, the $V_{\mathrm{O}}^{+}$capture electrons and transform into $V_{\mathrm{O}}^{\mathrm{X}}$. A blue emission $(\sim 450 \mathrm{~nm})$ band appears, resulting in brighter white light. Comparing the EL and PL spectra reveals four emission bands (blue, green, yellow, and red) whose variation can be attributed to $V_{\mathrm{O}}$, which is greatly influenced by the variation of the carrier concentration. ${ }^{15,26}$ Compared with the EL spectra, the emission bands in the PL spectra 

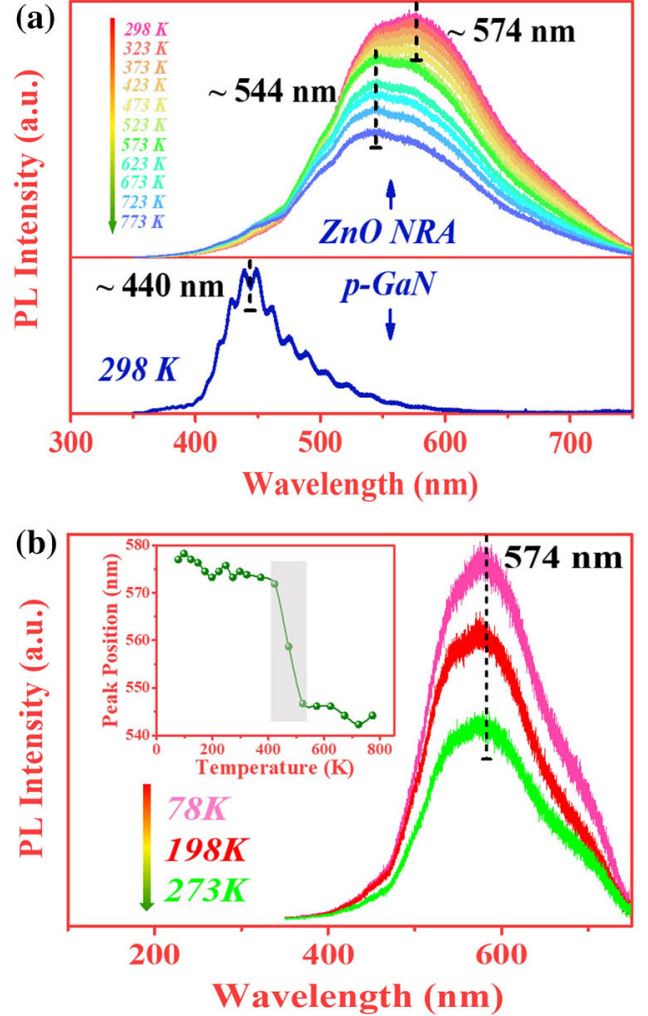

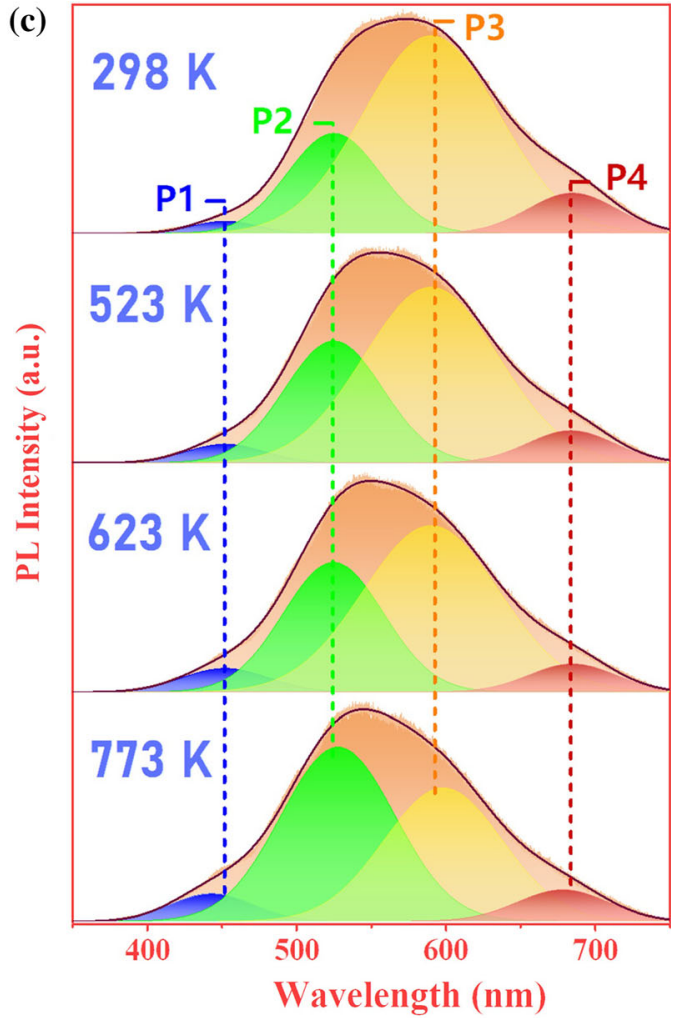

Fig. 3. (a) Temperature-dependent PL spectra of ZnO NRA and room-temperature PL spectra of $p$-GaN. (b) PL spectra under liquid-nitrogen conditions (inset shows temperature-dependent peak position of PL spectra; dark area indicates the $\sim 25$-nm blue-shift of the peak position). (c) Gaussian fitting results for PL spectra at different temperatures (Color figure online).

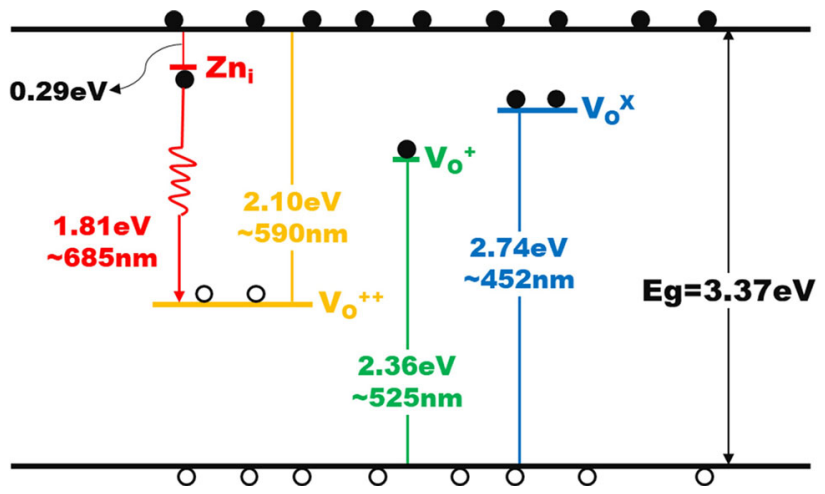

Fig. 4. Schematic energy band diagram of $\mathrm{ZnO}$ NRs.

exhibit some peak shift due to the different form of electronic transport. it is interesting to note that both $\mathrm{P} 4$ and $\mathrm{E} 4$ exhibit a red-shift of $0.4 \mathrm{eV}$, further indicating that the source of the red light is the transitional complex between $Z_{\mathrm{i}}$ and $V_{\mathrm{O}}^{++}$ (Fig. 4). As shown by the temperature-dependent PL (Fig. 3a and b) and bias-dependent EL (Fig. 2g) spectra, both the temperature and bias effect can lead to a blue-shift in the luminescence spectra, and temperature could indeed make a certain contribution to the EL peak shift. However, note that the peak showed a relatively small blue-shift $(\sim 30 \mathrm{~nm})$ from $\sim 574 \mathrm{~nm}$ to $\sim 544 \mathrm{~nm}$ in the temperature-

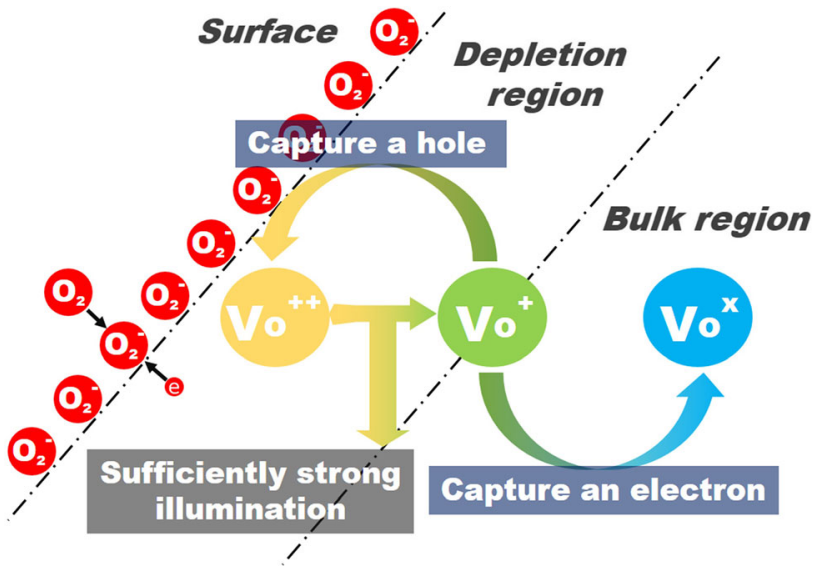

Fig. 5. Absorption model for ZnO NRA.

dependent PL measurements from $273 \mathrm{~K}$ to $773 \mathrm{~K}$, while the room-temperature EL spectra exhibited a blue-shift of almost $\sim 100 \mathrm{~nm}$ from $\sim 620 \mathrm{~nm}$ to $520 \mathrm{~nm}$ at relatively low bias from $0 \mathrm{~V}$ to $35 \mathrm{~V}$. This phenomenon indicates that the change in temperature is rather small to yield a blue-shift of more than $30 \mathrm{~nm}$ when the bias is less than $35 \mathrm{~V}$. It can therefore be concluded that the bias effect rather than the temperature effect dominates the light emission in the EL. 


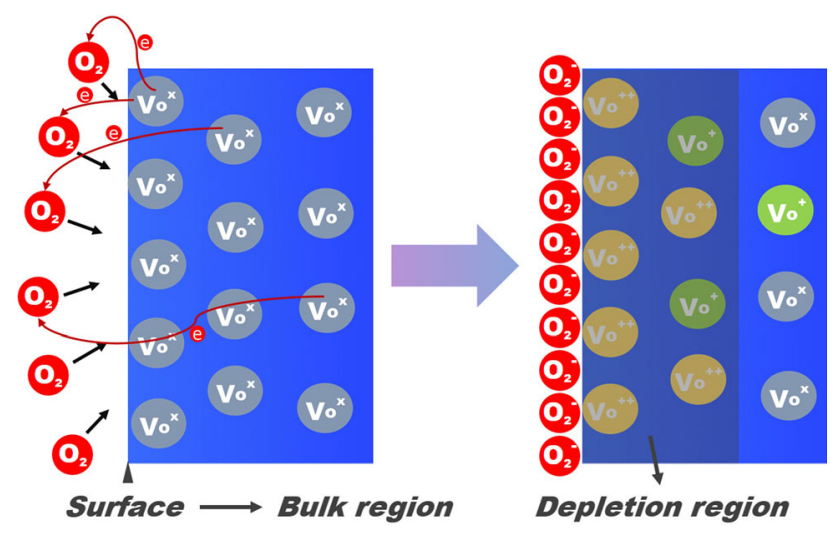

Fig. 6. $V_{\mathrm{O}}$ defect distribution and transformation model of $\mathrm{ZnO}$ NRs.

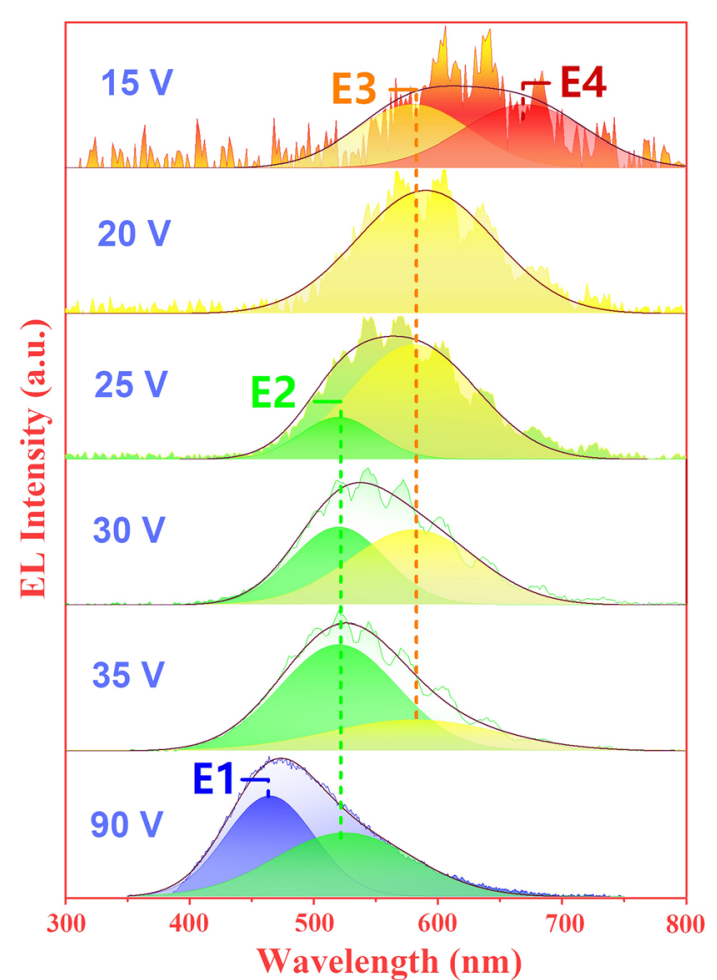

Fig. 7. Gaussian fitting results of EL spectra under forward bias of $15 \mathrm{~V}, 20 \mathrm{~V}, 25 \mathrm{~V}, 30 \mathrm{~V}, 35 \mathrm{~V}$, and $90 \mathrm{~V}$

\section{CONCLUSIONS}

A $p-\mathrm{GaN} / \mathrm{i}-\mathrm{MgO} / n-\mathrm{ZnO}$ heterojunction LED device was fabricated. The test results showed that it emitted high-brightness white light. The device was analyzed by four-peak fitting of the EL spectra under different forward bias voltages and hightemperature PL spectra. The location of the blue, green, yellow, and red luminescence emission bands in the schematic energy band diagram and a mechanism for the blue-shift in the luminescence spectra are proposed. The results of this study suggest a feasible approach for defect research in one-dimensional $\mathrm{ZnO} \mathrm{NRs}$ and provide a method for the preparation of white-light devices with adjustable chromaticity.

\section{ACKNOWLEDGMENTS}

This work was supported by the National Natural Science Foundation of China (Grant Nos. 51872187, 60976036, 21805194, 61704111, and 11774241), National Key Research and Development Program of China (Grant No. 2017YFB0400304), Natural Science Foundation of Guangdong Province (Grant Nos. 2016A030313060 and 2017A030310524), Fundamental Research Project of Shenzhen (Grant Nos. JCYJ20180305124701756, JCYJ20180305071822 48925, and JCYJ20180508163404043), and Science and Technology Foundation of Shenzhen (JCY J2016-2019).

\section{CONFLICT OF INTEREST}

The authors declare no competing interests.

\section{REFERENCES}

1. X. Yang, L. Dong, C.X. Shan, J.L. Sun, N. Zhang, S.P. Wang, M.M. Jiang, B.H. Li, X.H. Xie, and D.Z. Shen, Adv. Mater. 29, $1602832(2017)$.

2. J. Dai, C.X. Xu, and X.W. Sun, Adv. Mater. 23, 4115 (2011).

3. C. Zhang, Y. Qiu, W.Z. Liu, H.Y. Xu, L. Yang, C.L. Wang, and Y.C. Liu, Nanophotonics 8, 2203 (2019).

4. J.H. Choy, E.S. Jang, J.H. Won, J.H. Chung, D.J. Jang, and Y.W. Kim, Adv. Mater. 22, 15 (2003).

5. E. Lai, W. Kim, and P.D. Yang, Nano. Res. 1, 123 (2008).

6. H.C. Chen, M.J. Chen, Y.H. Huang, W.C. Sun, W.C. Li, J.R. Yang, H. Kuan, and M. Shiojiri, IEEE Trans. Electron Dev. 11, 58 (2011).

7. N.H. Alvi, K. Hasan, O. Nur, and M. Willander, Nanoscale Res. Lett. 6, 130 (2011).

8. A. Tsukazaki, M. Kubota, A. Ohtomo, T. Onuma, K. Ohtani, H. Ohno, S.F. Chichibu, and M. Kawasaki, Jpn. J. Appl. Phys. 21, 44 (2005).

9. X.M. Zhang, M.Y. Lu, Y. Zhang, L.J. Chen, and Z.L. Wang, Adv. Mater. 21, 2767 (2009).

10. X.Y. Chen, A.M. Ching, F. Fang, Y. Hang, A.B. Djurisic, H.L. Tam, K.W. Cheah, S. Gwo, W.K. Chan, P.W.K. Fong, H.F. Lui, and C. Surya, J. Appl. Phys. 110, 094513 (2011).

11. X.Y. Chen, M.C.N. Alan, A.B. Djurišić, W.K. Chan, P.W.K. Fong, H.F. Lui, C. Sury, C.C.W. Cheng, and W.M. Kwok, Thin Solid Films 527, 303 (2013).

12. O. Lupan, T. Pauporté, and B. Viana, Adv. Mater. 22, 3298 (2010).

13. S.J. Jiao, Y.M. Lu, D.Z. Shen, Z.Z. Zhang, B.H. Li, J.Y. Zhang, B. Yao, Y.C. Liu, and X.W. Fan, Phys. Stat. Sol. 4, 3 (2006).

14. S. Vempati, J. Mitra, and P. Dawson, Nanoscale Res. Lett. 7, 470 (2012).

15. K. Vanheusden, W.L. Warren, C.H. Seager, D.R. Tallant, and J.A. Voigt, J. Appl. Phys. 10, 79 (1996).

16. B. Panigrahy, M. Aslam, D. Misra, M. Ghosh, and D. Bahadur, Adv. Funct. Mater. 20, 1161 (2010).

17. C. Ahn, Y. Kim, D. Kim, S. Mohanta, and H. Cho, J. Appl. Phys. 105, 013502 (2009).

18. A.B. Djurisic, Y.H. Leung, K.H. Tam, Y.F. Hsu, L. Ding, W.K. Ge, Y.C. Zhong, K.S. Wong, W.K. Chan, H.L. Tam, K.W. Cheah, W.M. Kwok, and D.L. Phillips, Nanotechnology 18, 095702 (2007).

19. K.H. Tam, C.K. Cheung, Y.H. Leung, A.B. Djurisic, C.C. Ling, C.D. Beling, S. Fung, W.M. Kwok, W.K. Chan, D.L. Phillips, L. Ding, and W.K. Ge, J. Phys. Chem. B 110, 20865 (2006).

20. M.D.M. Cluskey and S.J. Jokela, J. Appl. Phys. 106, 071101 (2009).

21. Q. Zhu, C.S. Xie, H.Y. Li, C.Q. Yang, S.P. Zhang, and D.W. Zeng, J. Mater. Chem. C 2, 4566 (2014). 
22. K. Vanheusden, C.H. Seager, W.L. Warren, D.R. Tallant, and J.A. Voigt, Appl. Phys. Lett. 3, 68 (1996).

23. G. Chris, V.D. Walle, and J. Neugebauer, J. Appl. Phys. 8, $95(2004)$.

24. X. Liu, X.H. Wu, H. Cao, and R.P.H. Chang, J. Appl. Phys. 6, 95 (2004).

25. Z.M. Liao, C. Hou, Y.B. Zhou, J. Xu, J.M. Zhang, and D.P. Yu, J. Chem. Phys. 130, 084708 (2009).
26. Q. Zhu, C.S. Xie, H.Y. Li, and Q.C. Yang, J. Alloys Compd. 585, 267 (2014).

27. B. Deng, A.L. Rosa, T. Frauenheim, J.P. Xiao, X.Q. Shi, R.Q. Zhang, and M.A.V. Hoved, Nanoscale 6, 11882 (2014).

Publisher's Note Springer Nature remains neutral with regard to jurisdictional claims in published maps and institutional affiliations. 